LICENÇA CC BY: Artigo distribuído sob os termos

Creative Commons, permite uso e distribuição irrestrita em qualquer meio desde que $o$ autor credite a fonte original.

\title{
ESCRITA DE SI EM ROUSSEAU: LUGAR DE SOLIDÃO E AFIRMAÇÃO RADICAL DA PRÓPRIA EXISTÊNCIA
}

WRITING OF THE SELF IN ROUSSEAU: A PLACE OF SOLITUDE AND A RADICAL AFFIRMATION OF EXISTENCE ESCRITURA DE SÍ EN ROUSSEAU: LUGAR DE SOLEDAD Y AFIRMATIÓN RADICAL DE LA PROPIA EXISTENCIA

"Read me, do not let me die"

(Edna St. Vincent Millay)

Marlene de Souza Dozol ${ }^{1}$

Lia Presgrave Reis ${ }^{2}$

1Doutora em Educação pela USP. Docente do Programa de Pós-Graduação em Educação da Universidade Federal de Santa Catarina (UFSC), Florianópolis, SC, Brasil.

2Doutoranda em Educação pela Universidade Federal de Santa Catarina (UFSC),

Florianópolis, SC, Brasil.

Resumo: Neste artigo, serão discutidas questões de ordem estético-existencial observadas na leitura d'Os devaneios do caminhante solitário de Jean-Jacques Rousseau, tendo como interlocução o texto Jean-Jacques Rousseau: a transparência e o obstáculo de Jean Starobinski que, junto a outros comentadores, alimentarão o exame do tema da solidão nas reflexões sobre o autor. A solidão será compreendida aqui como energia autoformativa e sentimento que possibilita a expressão literária da autobiografia na obra rousseauniana. Elegeram-se algumas perguntas para nortear a reflexão: o que significaria uma escrita de si como lugar de solidão e como afirmação radical da própria existência em Rousseau? Que sentido atribuir à energia autoformativa de ambas quando se trata de uma mestria de si mesmo? Uma das formas de a escrita de si afirmar radicalmente a existência em Rousseau manifesta-se na sua obsessão pela "transparência", que o levou à conquista de uma unidade entre o próprio "eu" e a linguagem, na qual a palavra encarna o primeiro. Rousseau confunde sua existência com a própria essência da verdade, ao tomar as lembranças como matéria-prima para esses devaneios que adquirem forma literária, conferem autenticidade à obra e fabricam um discurso unificador, porque eivado de uma verdade do sentimento. Tal afirmação de si também inclui a decisão de narrar a sua vida para transmitir ao leitor uma informação mais autêntica de como se tornou quem é e porventura conseguir a remissão e o reconhecimento públicos. A escrita de si apareceria como lugar de solidão, ato de liberdade do escritor. A solidão irremediável do caminhante atuaria nos Devaneios como energia autoformativa, assumindo um valor estético e corroborando para um errante e inesgotável exercício de conhecimento do "eu" e da existência metamorfoseados em obra literária autobiográfica.

Palavras-chave: Solidão; Autobiografia; Jean-Jacques Rousseau. 
Abstract: This article aims to discuss issues of an aesthetic-existential order observed in the Reveries of the Solitary Walker (Jean-Jacques Rousseau). It also brings into the dialogue Transparency and Obstruction (Jean Starobinski) which, together with other commentators, promotes the examination of solitude in the reflections on Rousseau. Solitude is understood here as a self-formative energy and a feeling that allows the autobiography's literary expression in Rousseau's work. We have chosen a few questions to guide the discussion: what meaning would be given to a writing of the self as a place of solitude and a radical affirmation of existence in Rousseau's work? What meaning could we ascribe to the self-formative energy of both writings when it comes to the mastery of the self? One of the ways in which the writing of self radically expresses existence in Rousseau is his obsession with "transparency", which led him to the conquest of a unity between self and language, in which the word incarnates the self. Rousseau mingles his existence with the very essence of truth, by taking his memories as raw materials for reveries that acquire literary form, giving authenticity to the work and producing a unifying discourse as they become intertwined with a truth of sentiment. This selfaffirmation also includes the decision to narrate his own life in order to convey to the reader more authentic information on how he became who he is, and perhaps achieve remission and public recognition. The writing of the self would appear as a place of solitude, in other words, the writer's act of freedom. The irreparable solitude of the walker acts in the Reveries as a self-formative energy, assuming an aesthetic value and corroborating the erratic and endless exercise of knowledge of the "self" and of existence, metamorphosed into an autobiographical literary work.

Keywords: Solitude; Autobiography; Jean-Jacques Rousseau.

Resumen: En el presente artículo discutiremos cuestiones de orden estético-existencial, a partir de la lectura de Las ensoñaciones del paseante solitario de Jean-Jacques Rousseau, en diálogo con el texto Jean-Jacques Rousseau: la transparencia y el obstáculo de Jean Starobinski que, junto a otros críticos, contribuyeron con el estudio del tema de la soledad en las reflexiones sobre el autor. La soledad será entendida, en este trabajo, como energía autoformativa y sentimiento que posibilita la expresión literaria de la autobiografía en la obra rousseauniana. Elegimos algunas preguntas para orientar la reflexión: ¿Qué significa una escritura de sí como lugar de soledad y como afirmación radical de la propia existencia en Rousseau? ¿Qué sentido se le atribuye a la energía autoformativa de ambas cuando se trata de una maestría de sí mismo? Una de las formas de la escritura de sí que afirma radicalmente la existencia en Rousseau, se manifiesta en su obsesión por la "transparencia", que lo llevó a conquistar una unidad entre el propio "yo" y el lenguaje, en la cual la palabra encarna al "yo". Rousseau confunde su existencia con la propia esencia de la verdad, al tomar los recuerdos como materia prima para esas meditaciones que adquieren forma literaria, le confieren autenticidad a la obra y fabrican un discurso unificador porque está plagado de una verdad del sentimiento. Tal afirmación de sí también incluye la decisión de narrar su propia vida para transmitirle al lector una información más auténtica de cómo llegó a ser lo que es y, como consecuencia, para adquirir remisión y reconocimiento púbicos. La escritura de sí aparecería como un lugar de soledad, acto de libertad del escritor. La soledad irremediable del paseante actuaría en las Ensoñaciones como energía autoformativa, asumiendo un valor estético y contribuyendo para un errante e inagotable ejercicio de conocimiento del "yo" y de la existencia metamorfoseados en obra literaria autobiográfica.

Palabras clave: Soledad; Autobiografía; Jean-Jacques Rousseau. 


\section{Introdução}

No presente artigo, serão discutidas questões de ordem estético-existencial observadas na leitura d'Os devaneios do caminhante solitário de Jean-Jacques Rousseau, tendo como suporte a interlocução com Jean Starobinski em Jean-Jacques Rousseau: a transparência e o obstáculo que, junto a outros comentadores, alimentarão o exame do tema da solidão nas reflexões sobre o genebrino. A solidão será compreendida aqui não apenas como modalidade específica de existência, mas igualmente como energia autoformativa e sentimento que possibilita a expressão literária da autobiografia no interior da obra de Rousseau ${ }^{1}$. Feitas essas observações iniciais - com o fito de melhor definir o gênero para então fazer emergir a especificidade ou a originalidade de Rousseau - convém recuperar as perguntas que norteiam a presente reflexão: o que significa uma escrita de si como lugar de solidão e como afirmação radical da própria existência em Jean-Jacques Rousseau? Que sentido atribuir à energia autoformativa de ambas quando se trata de uma mestria de si mesmo?

Pode-se dizer, sem o menor receio, que os escritos autobiográficos de Rousseau, notadamente os Devaneios, empreendem o exercício de uma narrativa de si de modo notadamente romântico, na qual a subjetividade brota como campo semântico e o teor de dramaticidade do texto encontra no lirismo a sua forma mais bem-acabada de expressão ${ }^{2}$, propondo, de fato, uma determinada estética de existência ${ }^{3}$. Pode-se igualmente compreender tal estética como estratégia literária utilizada por Rousseau para realizar um denso inventário pessoal repleto de reflexões cujo interesse volta-se para o sentido de sua existência em busca de repouso, plenitude e unidade com a natureza que é, para ele, a Ordem no sentido de uma "metafísica" ligada à existência:

Essas horas de solidão e de meditação são as únicas do dia em que sou plenamente eu mesmo e em que me pertenço sem distração, sem obstáculos e em que posso verdadeiramente dizer que sou o que desejou a natureza (ROUSSEAU, 1995, p. 31).

Isso, também relativamente à sua reforma moral: "[...] resolvi submeter meu íntimo a um exame severo que o determinasse para o resto de minha vida assim como desejaria encontrá-lo no momento de minha morte" (ROUSSEAU, 1995, p. 44). Ou simplesmente: "Mas eu, afastado [...] de tudo, que sou eu mesmo? Eis o que me falta procurar" (ROUSSEAU, 1995, p. 23).

Entretanto, o que seria mesmo essa existência? Acredita se tratar de um fenômeno único em cada indivíduo e que, assim como a solidão, exige ser experienciado para ser compreendido. Daí que a existência não pode ser propriamente conceituada, pois sendo relativa a cada ser, não pode ser entendida de modo unívoco. Poder-se-ia designá-la um modo de ser fundamental do humano em sua relação consigo mesmo, com o mundo e o absoluto (esta última uma relação contingente e nunca necessária). Um dos grandes problemas da existência é a liberdade, pois o homem somente tem a posse de si mesmo 
quando num ato de vontade realiza a plenitude de seu ser. Desse modo, o sentido da existência a ser discutido configura uma essência do "eu" encontrada no querer e não apenas no pensar, visto que apenas por meio do querer se abrem a plenitude e a profundidade do sentimento de existência. Assim, Baczko conclui que Rousseau, a despeito de não abandonar o seu racionalismo, substitui o cogito cartesiano pelo sentimento de existência para a compreensão ontológica do humano e da verdade de si:

\footnotetext{
Ao "eu penso, logo eu existo" de Descartes, à consciência de si considerada como a consciência da atividade intelectual, Jean-Jacques Rousseau não opõe o procedimento dos sensualistas, que reduz a existência ao ato, ou à série de atos da percepção sensível. A consciência de si é o ponto de partida de toda reflexão filosófica, mas o que é inicialmente dado é o sentimento do eu, e não os atos de pensamento ou da percepção sensível (BACZKO, 1974, p. 213, trad. nossa).
}

\title{
Alguns sentidos da solidão nos Devaneios
}

A solidão nos Devaneios é polissêmica e relativa. Assim, ela nunca pode ser pensada sob uma forma absoluta. Seu grande contraponto do qual necessita para se alimentar e crescer em força e virtude é a sociedade degenerada, imagem que sempre acompanha Rousseau em suas reflexões mais hostis sobre a vida citadina e os costumes dos homens de seu tempo e dos quais ele jamais se desprenderá completamente. $\mathrm{O}$ coração de Rousseau não logra uma atitude estoica de inteiro abandono da sociedade e de suas mazelas, porque necessita do reconhecimento do outro para atestar a virtude do seu esforço de reforma moral. Rousseau deseja persuadir o público a respeito da sua inocência diante das acusações e reveses que sofreu relativos às suas escolhas pessoais e às suas obras. Jean-Jacques, não raras vezes, encontra-se vinculado à sociedade por afecções de agressividade e revolta que ora se revelam circulares e obsessivas, peculiares à amargura, à decepção e à tristeza de um presente infeliz; ora se transformam em energia geradora para uma mestria de si mesmo e para a criação de uma obra literária. A afirmação radical de si, de sua inocência, de sua transparência emerge e se fortalece nesse perpétuo contraste com o "mal":

\begin{abstract}
[...] todas as felizes disposições que a natureza colocou em meu coração são transformadas por meu destino e por aqueles que dele dispõem, em prejuízo de mim mesmo ou de outrem, não mais posso olhar uma boa ação que me pedem senão como uma armadilha que me armam e sob a qual está escondido algum mal. Sei que, seja qual for o efeito da ação, não deixarei de ter o mérito de minha boa intenção (ROUSSEAU, 1995, p. 85).
\end{abstract}

Para Tzvetan Todorov (2005, p. 94), em seu livro O jardim imperfeito: o pensamento humanista na França, a causa da solidão de Rousseau não está nele e sim nos demais. Esses outros que o "privaram" de uma comunicação autêntica recusaram o pacto social; esses outros que o "obrigaram" a substituir convívios desqualificados pelo convívio com a natureza, pela evasão no imaginário, pela escrita... são também os outros que o "acompanham", que dele exigem explicações, que o julgam, podendo fazer um mau uso dos seus escritos, o que o leva a preocupar-se com sua recepção pela posteridade. 
Estaria Rousseau realmente só? Tal pergunta pode ser estendida a todos aqueles que escolhem a escrita como trabalho e acabam por caracterizá-la como "atividade paradoxal que exige que se fuja dos outros para melhor encontrá-los" ou, dito de modo semelhante, a "solidão é ainda uma maneira de viver com outros" (idem, p. 108). Nos Devaneios, "experiência privada e extrema" - na expressão de Todorov (idem, p. 99) - e que "aspira a um puro sentimento de ser" (idem, p. 98), a solidão aparece como um retorno ao ideal rousseauniano de transparência total alheio a qualquer sujeição a máscaras sociais ${ }^{4}$, e como resposta vivida à sua negação da sociedade e efeito de uma crítica contundente à cultura:

Esforcei-me por expor a origem e o progresso da desigualdade, o estabelecimento e o abuso das sociedades políticas [...]. Conclui-se [...] que, sendo quase nula a desigualdade no estado de natureza [na solidão do isolamento social], deve sua força e seu desenvolvimento a nossas faculdades e aos progressos do espírito humano, tornando-se afinal, estável e legítima graças ao estabelecimento da propriedade e das leis (ROUSSEAU, 1973, p. 288).

Em outras palavras, quanto mais o filósofo bradava contra a degeneração moral e a transparência perdida da sociedade de seu tempo, mais distanciado dela e errante ele se tornava, tanto porque se considerava deslocado e inepto para a convivência com os demais, e igualmente porque, de fato, como já indicado, fora perseguido devido ao conteúdo de sua obra considerada transgressora, sendo censurada em alguns países europeus à época. No tocante à perseguição à pessoa de Jean-Jacques, Starobinski faz uma importante observação. Ao ter afirmado que a sociedade é contrária à natureza, Jean-Jacques colocou-se consequentemente como um opositor da sociedade, comunicando a seguinte mensagem: "eu me oponho à sociedade" (STAROBINSKI, 1991, p. 485). Retirar-se da vida social significava para Rousseau um modo de poder direcionar sua crítica à sociedade com a legitimidade de um homem que se colocava externamente a ela na posição de um paradigma de virtude para os outros. Rousseau quis assumir a imagem da antítese do mal aos olhos da sociedade, fazendo-a recordar o bem que ela havia esquecido ou porventura ignorado. Segundo Starobinski, a "tensão trágica, em Rousseau, não resulta apenas da própria separação e ruptura, mas da necessidade de fazer coincidir a todo momento sua solidão com o bem e a verdade essenciais, tais como os reconhece em seu foro íntimo" (STAROBINSKI, 1991, p. 52). Assim, Rousseau falha na tarefa de justificar sua solidão. Gradualmente, dá a impressão de deixar de lutar pelo reconhecimento da sociedade e até mesmo da posteridade: "Logo que comecei a entrever a trama [referência ao complô universal que julga terem urdido contra ele] em toda a sua extensão, perdi para sempre a ideia de, ainda em vida, trazer de volta o público para a minha pessoa" (ROUSSEAU, 1995, p. 25). Ao fim de sua vida, para isso só contará com o auxílio de deus e da sua consciência (STAROBINSKI, 1991), sem desistir, contudo, de perseguir sua própria justificação e reconhecimento.

A obra rousseauniana encarna uma virada existencial quando o problema da solidão aparece da forma trágica e dramática peculiar aos Devaneios. O tema já apareceria, por exemplo, no Discurso sobre a origem e os fundamentos da desigualdade entre os homens ${ }^{6}$ e em Emílio ou Da Educação, todavia de maneira distinta, porque refletida do ponto 
de vista social, político e educativo ${ }^{7}$ na esperança de uma correção de rumo. Diante da impossibilidade histórica de recuperar a unidade perdida na máscara das relações sociais e, consequentemente, de alcançar a felicidade que a vida mundana não lhe havia proporcionado, Jean-Jacques volta-se para sua interioridade ao escolher o isolamento como condição existencial. Não sendo possível transformar o mundo exterior, o seu recurso é a reforma interior (moral), visando à redenção individual. Em outras palavras, a saída estaria na relação imediata que a subjetividade poderia construir com ela mesma, com a ideia do imediato associada ao desejo de transparência que sempre acompanhou o genebrino. Nesse aspecto, a solidão é necessária porque permite o acesso à razão, à liberdade e à natureza (STAROBINSKI, 1991). A razão defendida por Rousseau representa um espaço de clareza de ideias - não vislumbrado por ele na sociedade - o qual, num estado de isolamento, pode auxiliá-lo a compreender o sentido da sua existência. Trata-se de uma "razão intuitiva, [mais profunda], capaz de iluminação 'imediata' " (STAROBINSKI, 1991, p. 52-53), conciliável com o sentimento, porém oposta à ideia de uma razão discursiva e instrumental.

Apesar da peculiaridade assumida pelo problema da solidão nos Devaneios, considerando-se os exemplos inicialmente citados, no Segundo Discurso a solidão do estado de natureza é condição para a realização do experimento mental e conjectural visando ao "encontro" com o homem natural. No Emílio, essa condição alia-se ao esforço de eliminar todas as variáveis que possam comprometer a "infância-constructo", arquétipo do homem natural passível de reedição mesmo numa sociedade degenerada, bem como de uma condução especificamente pedagógica que deverá desdobrar uma natureza inicial e virtual em virtudes sociais. Em ambos os casos e, não se levando em conta os belíssimos arranjos que a prosa poética do autor dá a fruir, a solidão em parceria com o silêncio aparecem como uma espécie de "energia" impressionista que, ao se evolar da paisagem, permitem ambos os "experimentos", se se refletir sobre a generosa porção de racionalidade aí implicada.

Se fosse possível localizar o tema da solidão em Rousseau, poder-se-ia captar seus primeiros sinais naquela constatação de que a sociedade é contrária à natureza, vivida como um sentimento de existência no sentido de uma profunda experiência de solidão. Diante disso, o filósofo, homem entre os homens, se levanta como legítimo intérprete de uma verdade maior relacionada a valores universais de liberdade, virtude e natureza os quais, segundo ele, deveriam ser comunicados aos demais por meio de uma palavra forte, dissonante e até mesmo profética por um lado (STAROBINSKI, 1991), mas, por outro, observa-se que esta mesma palavra inaugurava uma vida de errância na medida em que sua existência tornava-se inconciliável com os ditames e as desilusões advindas de suas frustações com a sociedade. Apesar disso, o interesse desta reflexão volta-se para a errância rousseauniana que irrompe em obra. Intenta-se descobrir como a errância dos Devaneios do caminhante solitário é ressignificada de modo a, de posse desse sentimento 
fundamental de solidão, irromper em uma escrita de si, cuja expressão literária afirmará radicalmente a própria existência de Jean-Jacques. Lembra-se de que o outro objetivo deste artigo trata de compreender como, em Rousseau, a solidão irremediável do caminhante, ancorada sob um profundo sentimento de existência, atuaria nos Devaneios como energia autoformativa, corroborando para um perpétuo e inesgotável exercício de conhecimento do "eu" que apareceria sob a forma de obra literária autobiográfica.

\section{Escrita de si, solidão e existência}

Viu-se que uma escrita de si - igualmente compreendida como a arte de traduzir um puro sentimento de ser - é um lugar de solidão nos Devaneios do caminhante solitário e que, apesar de todo o apelo da obra ao convencimento público, a escrita das meditações dos Devaneios é, sobretudo, um encontro do "eu" consigo mesmo na tentativa de encontrar o sentido de sua existência. Nas palavras de Starobinski:

O devaneio de Rousseau trabalha para apagar essa exterioridade [entre a consciência conhecente e o ser conhecido] [...]. Conversar consigo mesmo [...] será o fim supremo, o objetivo insuperável. E a escrita que fixa o devaneio será o suporte desse encontro do mesmo com o mesmo (STAROBINSKI, 1991, p. 3718).

Ao se mencionar a solidão, não se designa apenas sua feição trágica, mas igualmente o sentido de um exercício de um gênero específico de escrita, o qual experimenta a solidão como condição existencial do humano. Nessa escrita, Rousseau está a todo momento autocentrado, autorreferente. $O$ caminhante solitário escreve sobre si mesmo e fala sobretudo para si mesmo. Em meio a um vazio existencial que Jean-Jacques deseja ver preenchido, na impossibilidade de encontro real com os outros, ou melhor, de se reconhecer neles, o livre pensador deseja nutrir-se de sua própria substância.

Segundo ele próprio, sua escrita, em parceria com o silêncio e a solidão, pediria um profundo mergulho na interioridade para se realizar: "A obra que empreendia somente podia ser executada num retiro absoluto; exigia longas e calmas meditações, que o tumulto da sociedade não suporta" (ROUSSEAU, 1995, p. 44). Talvez o maior préstimo que se poderia conceder à escrita de si como lugar de solidão seria considerá-la na verdade o que ela já o é, ou seja, um ato de liberdade do escritor. Portanto, o lugar de solidão dos devaneios é a liberdade frente a toda e qualquer sujeição, bem ao gosto da personalidade de Rousseau. Como mencionado anteriormente, somente por meio de um ato de vontade livre se abrem a plenitude e a profundidade do sentimento de existência. Não seria demais repetir que o lugar de solidão dos devaneios é a liberdade.

Se essa liberdade não encontra espaço no mundo exterior, como ocorre no caso de Jean-Jacques, possibilitá-la, mais do que nunca, significa a decisão de procurar em si mesmo e encontrar aí a matéria-prima para escrever sobre si mesmo. Nas palavras do próprio Rousseau:

Reduzido unicamente a mim, alimento-me, é verdade, de minha própria substância, mas ela não se esgota e eu me basto a mim mesmo ainda que rumine [...] sem assunto e ainda que minha imaginação esgotada e minhas ideias extintas não forneçam mais alimento a meu coração (ROUSSEAU, 1995, p. 106). 


\section{É Starobinski quem o esclarece:}

Resta, no entanto, um refúgio para a liberdade: o sentimento interior, e o próprio ato de escrever. Se a liberdade não é o princípio que Rousseau vê em ação em sua vida, é aquele que lhe tornará possível a expressão literária. Rousseau [...] considera a sua vida como um destino imposto por uma sorte temível; mas a autobiografia será um ato de liberdade; dirá a verdade sobre si mesmo porque se afirmará livremente em seu sentimento, porque não aceitará nenhuma coerção, nenhum embaraço, nenhuma regra (STAROBINSKI, 1991, p. 2019).

O "eu", portanto, não é fruto da imaginação, tampouco revelado pelas ideias: é sentimento, ou melhor, é sentimento de si. Mas como passar desse sentimento para a sua expressão? Na retórica de Rousseau, a linguagem adquire uma "força moral" (PRADO JR., 2008, p. 134), tendo o critério de verdade migrado de uma ideia de veracidade para a de autenticidade dos fatos narrados, os quais asseguram ao "eu" a legitimidade para narrar a própria existência à sua maneira (porque ele mais do que ninguém a conhece ou sente), levando em consideração mais uma verdade do sentimento - que ao ser revivido por vezes amplia, recria, acrescenta e adorna as lembranças - do que a verdade dos fatos. Conforme Starobinski (1991, p. 201), a "possibilidade de alcançar o verdadeiro reside nessa liberdade da palavra e no movimento espontâneo da linguagem" ou de uma linguagem que se deseja espontânea. É como se por meio da palavra ele pudesse tocar e transformar tudo que estivesse em seu poder. A palavra erige, institui, cria reinos.

E o que sustentaria uma escrita de si como afirmação radical da própria existência em Jean-Jacques Rousseau? A obsessão do genebrino pela transparência total e pela experiência imediata levou-o à conquista de uma unidade entre o "eu" e a linguagem, esta última concebida como signo aberto que se dá a superfícies, obra de um "sentimento [que] [...] se manifesta abertamente a partir do instante em que é experimentado" (STAROBINSKI, 1991, p. 188). Há, assim, uma unidade entre sujeito, linguagem e emoção, na qual a palavra encarna o próprio "eu":

O sujeito é sua emoção, e a emoção é imediatamente linguagem. Sujeito, linguagem, emoção já não se deixam distinguir. A emoção é o sujeito que se desvela, e a linguagem é a emoção que se fala. $\mathrm{Na}$ inspiração narrativa, Jean-Jacques é imediatamente sua linguagem [porque aspira à transparência] (STAROBINSKI, 1991, p. 202).

O que Rousseau pretende ao buscar dizer-se? Reeditar aquele momento primordial no qual a linguagem, originariamente, brota das paixões, conforme conjectura em seu Ensaio sobre a origem das línguas ${ }^{10}$ ? Acreditamos que sim. Afinal, sua autobiografia não poderia ser comparada a um canto da alma?

A afirmação radical de sua existência inclui, sobretudo, a decisão do genebrino de narrar a própria vida: "[...] [A Rousseau] parece-lhe apenas que é impossível afirmar-se sem se narrar, e que a narração do detalhe de sua vida 'passará' melhor que a afirmação global 'sou inocente'" (STAROBINSKI, 1991, p. 196). Como explica Starobinski, escrever uma autobiografia poderia ter sido para Jean-Jacques um modo de, ao contar com detalhe e autenticidade a sua experiência de vida, poder transmitir ao leitor uma informação mais ampliada e completa de como se tornou quem é (para tentar direcionar o julgamento 
do leitor a seu favor) ou que espécie de vida por viver fora exigida desta obra que se perfaz no momento da leitura diante do leitor. Resta a este último o problema de ser apresentado a um "eu" que, por sua vez, apresenta-se como a própria projeção do real...

A afirmação radical da existência desse "eu" errante estaria igualmente expressa, segundo Starobinski, na necessidade de

[...] conquistar a certeza de uma relação essencial com a verdade, isto é, confundir a existência pessoal com a própria essência da verdade, produzir uma palavra em que o eu se afirmaria apenas para desaparecer numa transparência impessoal, através da qual valores eternos se manifestariam: liberdade, virtude... (STAROBINSKI, 1991, p. 55).

Além disso, em relação às lembranças - matérias-primas não do devaneio primeiro (a experiência em si), mas do "devaneio segundo" —, uma vez que adquirem forma literária mediante a escrita, o passado e a escritura se fundem para conferir autenticidade à obra. Esta recupera os elementos do devaneio primeiro e de uma imaginação criadora - porém difusa —, a fim de dominá-los e, unificando-os, transpôlos para a escrita com o intuito de fabricar um ritmo semelhante ao do pensamento e inventar um discurso homogêneo, unificador "no seio do qual tudo viria a compensar-se e igualar-se" porque entremeado por uma verdade do sentimento, conforme preconizava Rousseau. O passado é reacontecido e ressignificado na escrita do presente e ao mesmo tempo é substância para que ela aconteça (STAROBINSKI, 1991, p. 365). Dessa maneira, a unidade reconquistada projeta-se "retrospectivamente sobre a existência inteira", reestruturando-se de forma a assemelhar-se à própria obra. Assim, obra e existência quase não se distinguem mais porque se fundem motivadas por um infindável desejo de transparência que se exaure em si mesmo e extrai do próprio esgotamento a sua energia criadora $^{11}$ (STAROBINSKI, 1991, p. 365).

\section{Transmutação purificante e escrita de si}

De que maneira, em Rousseau, a solidão irremediável do errante caminhante, ancorada sob um profundo sentimento de existência, atuaria nos Devaneios como energia autoformativa, corroborando para um perpétuo e inesgotável exercício de conhecimento e afirmação radical do "eu" e da existência que apareceriam sob a forma de autobiografia?

A ideia de transmutação purificante pareceu promissora para refletir acerca do processo criador da escrita de si, ou seja, sobre a potência criadora que emerge ressignificada em devaneios e que atua como energia autoformativa do caminhanteescritor, tendo como ponto de partida o sentimento de uma solidão fundamental. Starobinski considera transmutação purificante

[...] o trabalho psíquico do devaneio [que] consiste sempre em passar de um estado de perturbação e de conflito a um estado de simplicidade límpida [transparência]. Temos aqui o elemento invariável, o denominador comum das formas mais diversas do devaneio. Sob esse aspecto, o devaneio segundo 
equivale ao devaneio primeiro; não Ihe é inferior, com a diferença de que o devaneio primeiro opera em plena crise, no instante presente, enquanto que o segundo opera a frio, no universo das "segundas intenções", isto é, na lembrança ou na nostalgia das imagens amadas, na representação diferida dos sentimentos. Aliás, essa distinção não é absoluta, pois o devaneio primeiro, em seus transportes mais intensos, recorre constantemente à reflexão para tomar recuo em relação às etapas inferiores da aventura mental; é preciso abolir e reprimir no passado as imagens e os sentimentos acima dos quais o pensamento se eleva para ter acesso à transparência: então, é preciso continuar a pensar o que foi, para melhor provar, por contraste, do êxtase presente. Em compensação, o devaneio segundo não se desenvolveria se não tivesse em sua origem um sentimento atual (de inquietação, de angústia, de incerteza, etc.), que o incite a buscar socorro em uma realidade distante: o passado fora de alcance, os êxtases findos, as delícias impossíveis, o fantasma das emoções, o antigo projeto de escrever. Ele não se desenvolveria se não tivesse por objetivo criar aqui mesmo, nas palavras que encadeia, a convicção doce-amarga da serenidade reconquistada (STAROBINSKI, 1991, p. 365-36612).

O comentador apresenta, em pouquíssimas palavras, uma fórmula para a compreensão do fenômeno da transmutação purificante: "Converter a dor em volúpia", algo como um trabalho de significar outra vez essa dor de modo a convertê-la em criação de algo inaudito, inovador, atribuindo novo sentido a essa primeira vivência negativa. Verificou-se que, na escrita dos Devaneios, Rousseau vive esse processo de forma exemplar, ainda que tenha consciência dos próprios limites:

Reduzido unicamente a mim, alimento-me, é verdade, de minha própria substância, mas ela não se esgota e eu me basto a mim mesmo ainda que rumine [...] sem assunto e ainda que minha imaginação esgotada e minhas ideias extintas não forneçam mais alimento a meu coração (ROUSSEAU, 1995, p. 106).

Como anteriormente mencionado, o trabalho de transmutação precisa do elemento essencial, isto é, o conflito, a sombra, a dor que se metamorfoseia em criação. Tal processo necessita desses abismos para crescer e se propagar em uma energia vital que contrastará com a opressão da qual o genebrino tenta se libertar. Segundo Starobinski (1991, p. 372), "Rousseau tem necessidade de mergulhar novamente na dor para elaborar ativamente, voluptuosamente sua libertação da dor". A transmutação purificante é uma forma de ressignificação da experiência do sofrimento a qual, nos Devaneios, assume um valor estético que "arrasta a consciência sonhadora" (STAROBINSKI, 1991, p. 365), visando à elaboração de uma escrita de si.

Podemos ainda pensar que essa escrita de si abre portas para um exercício de originalidade na medida em que se contrapõe aos outros, às suas vãs opiniões e aos seus falsos valores. Aqui, a solidão, longe de ser temida, é "companhia" benfazeja que exerce sobre o "eu" um trabalho secreto e lento orientado, sobretudo, pelas promessas envolvidas na autodescoberta que é sempre continuada e realizada na feitura de uma obra. Ainda que suas resultantes demorem, seria preciso, lembrando Rainer Maria Rilke, confiar nela e alegrar-se com o crescimento dela advindo. Em Cartas a um jovem poeta $^{13}$ (1903-1908), Rilke compreende a solidão como um repouso e um lar: é preciso habitá-la para, inclusive, recuperar-se da multidão pretenciosa que fala e tagarela. Nele, a solidão assume valor de grandeza, de fármaco, de um labor sobre um acontecimento íntimo, de uma comunhão com as coisas e, graças a ela, o indivíduo solitário estaria irremediavelmente submetido a leis profundas. 
Tais considerações não seriam, de modo algum, estranhas a Rousseau, ainda que misturadas, no seu caso, a um tom de lamento que por vezes resvala em vitimização e que, certamente, carrega os acentos patológicos que sempre retornam em meio à ilusão de uma estabilidade que se prolongaria infinitamente aos moldes de sua estada na ilha de Saint-Pierre (Quinta Caminhada dos Devaneios), na qual o filósofo — que tem a si mesmo como matéria-prima de pensamento e de autoeducação - se disse de fato feliz e em paz. A escrita dos Devaneios é ao mesmo tempo solar e sombria como o seu autor. Como nós.

\section{Conclusão}

"Read me, do not let me die" - eis a epígrafe que inicia o texto. De fato, Rousseau desejava ser lido, não queria ser esquecido, e mais, gostaria de ser lembrado com a distinção que julgava merecer a despeito de todo o seu discurso que proclamava a destruição da glória comum dos homens. Mas ele também era um homem e, sobretudo, um homem de paradoxos. Rousseau não queria ser desmentido ou, pior ainda, aniquilado. Escreveu para continuar falando, às vezes para os outros dele mesmo, outras vezes para si, a fim de defender sua integridade ou o que dela restou. Contudo, nas suas palavras, por vezes transparece uma dignidade tão inabalável que a existência mais detestável jamais pareceria derrubar e nisso também residia a sua grandeza retórica. E sua escrita é a convicção concomitantemente artificiosa e genuína desse pensamento.

A escrita de Rousseau está imersa nessa tensão por um obsessivo desejo de transparência que jamais se realizaria, pois a linguagem é por natureza cifrada, sempre indireta, porque sua expressão é simbólica, arbitrária. Felizmente, enquanto o artista se utiliza de sua capacidade de superação como a um vício para vencer a si mesmo, ser maior do que o seu deus ou o deus das coisas, aos leitores resta o produto desse labor: as obras.

O desejo pela transparência encontrado por Rousseau somente nas águas cristalinas das margens do lago de Bienne ou nas ínfimas estruturas de uma folha ou de uma flor; nos córregos que banham a superfície do Eliseu (jardim à moda inglesa que Rousseau dá a conhecer numa das cartas que compõem o romance epistolar Júlia ou a Nova Heloís $\left.a^{14}\right)$; ou ainda numa criança, quer dizer, em naturezas que se dão a ver sem reservas e que se metamorfoseiam, na escrita autobiográfica de Rousseau, em "espelhos" de si mesmo, tudo isso é irrealizável na sociedade dos homens. Mas é o seu afã pela transparência que sustém o perpétuo impulso do recomeçar da escritura. Em outras palavras, ele mantém o escritor no labor da escrita, com esse horizonte em mente. Se, por um lado, tal desejo de manifestação tornam infindáveis a escritura de si e a reflexão sobre a própria existência, por outro ele é o que garante a permanência de um "eu" que não pode deixar de dizer de si na esperança sempre malograda de dizer o indizível e, de algum modo, prolongar-se, existindo fora de si mesmo, nos outros. 


\section{Referências}

BACZKO, B. Rousseau. Solitude et communauté. Paris: La Haye, Mouton, 1974.

BOSI, A. O ser e o tempo da poesia. São Paulo: Cultrix, EDUSP, 1977.

LEJEUNE, P. O pacto autobiográfico: de Rousseau à internet. Traduções de Jovita Maria Gerheim Noronha e Maria Inês Coimbra Guedes. Belo Horizonte: Editora UFMG, 2014.

PRADO JR., B. A força da linguagem. In: PRADO JR., B. A retórica de Rousseau. São Paulo: Cosac Naify, 2008.

ROUSSEAU, J. J. Discurso sobre a origem e os fundamentos da desigualdade entre os homens [1755]. Tradução de Lourdes Santos Machado. São Paulo: Abril Cultural, 1973. (Coleção "Os Pensadores", XXIV).

Emílio ou Da Educação [1762]. Tradução de Roberto L. Ferreira. 3. ed. São Paulo: Martins Fontes, 2004.

Os devaneios do caminhante solitário [1782]. Tradução, introdução e notas de Fúlvia Maria Luiza Moretto. 3. ed. Brasília: Editora Universidade de Brasília, 1995.

STAROBINSKI, J. Jean-Jacques Rousseau: a transparência e o obstáculo. Tradução de Maria Lúcia Machado. São Paulo: Companhia das Letras, 1991.

TODOROV, T. O jardim imperfeito: o pensamento humanista na França. Tradução de Mary Amazonas Leite de Barros. São Paulo: Editora da USP, 2005.

Artigo recebido em: 18/02/2019

Aprovado em: 15/04/2019

Contato para correspondência:

Lia Presgrave Reis. E-mail: liapresgrave@gmail.com

Notas

1 As primeiras análises de Philippe Lejeune (2014, p. 16) definem a autobiografia como uma "[...] narrativa retrospectiva em prosa que uma pessoa real faz de sua própria existência, quando focaliza sua história individual, em particular a história de sua personalidade". Essa história abrange uma narrativa íntima que extrapola a narração de fatos concretos ou memórias de uma vida. Desse modo, o assunto primordial da autobiografia é a gênese de uma personalidade, criação a qual, na tentativa de responder à pergunta "Quem sou eu?", o autobiógrafo a desdobraria na indagação "Como me tornei assim?" (LEJEUNE, 2014, p. 63-64). A autobiografia pode ser analisada a partir de quatro categorias. São elas: a forma da linguagem, devendo ser uma narrativa em prosa; o assunto tratado, a história de uma personalidade; a situação do autor, a de identidade entre autor (pessoa real) e narrador, sendo então ambos a mesma pessoa tanto factualmente quanto discursivamente; e, por último, a posição do narrador, a de identidade entre o narrador e o personagem principal (geralmente expressa pelo emprego da primeira pessoa, podendo posteriormente ser convertido em nome próprio), bem como a perspectiva retrospectiva da narrativa. Conforme prevê Lejeune (2014), para ser classificada autobiográfica, uma obra precisa preencher simultaneamente todas essas condições. Supõe-se, portanto, uma relação intrínseca de identidade entre o autor, o 
narrador e o personagem. Importa destacar que o texto autobiográfico jamais pode ser anônimo, pois a categoria nome próprio é fulcral tanto para a construção por parte do autor e como compreensão por parte do leitor desse tipo de discurso. Lejeune (2014, p. 39) explica que ambos, leitor e autor, compreendem a autobiografia mediante um "contrato de identidade selado pelo nome próprio". Assim, não há sentido em escrever a história de uma vida - que de fato existiu e cuja exposição se deseja verdadeira ainda que a narração dos fatos não seja fidedigna -, ocultando o nome do seu autor. Aqui, o desejo de verdade é uma das categorias que diferenciam a autobiografia clássica da ficção clássica. A menção ao nome próprio refere-se ao nome do autor impresso na capa do livro e na folha de rosto, assinatura a qual remete à realidade extratextual indubitável da pessoa real, autora da obra, portanto responsável pelo seu conteúdo. Lejeune (2014, p. 26-27) afirma ser capital o lugar concedido a esse nome, visto que "ele está ligado, por uma convenção social, ao compromisso de responsabilidade de uma pessoa real, ou seja, de uma pessoa cuja existência é atestada pelo registro em cartório e verificável". Chega-se finalmente à ideia de pacto autobiográfico, essencial a qualquer autobiografia, para definir a afirmação da identidade do nome (autor-narrador-personagem) no texto, remetendo ao nome do autor escrito na capa do livro, bem como à compreensão do leitor na recepção desse tipo autobiográfico de narrativa. Essa relação estabelecida entre autor e leitor caracterizaria igualmente o que Lejeune denomina pacto autobiográfico. Enfatizando ainda a importância da expressão da primeira pessoa na autobiografia clássica, edificada na manifestação do nome próprio do autor, Lejeune afirma que o tema profundo subjacente à autobiografia é o nome próprio. O texto autobiográfico, por definição, ao fundir autor e pessoa, desperta neste uma "paixão pelo nome próprio [...] já que, através dela, é a própria pessoa que justifica sua existência" (LEJEUNE, 2014, p. 39-40, grifos do autor). Daí advém a proposição desse artigo de vislumbrar na autobiografia a expressão de uma estética rousseauniana de existência.

2 Em O ser e o tempo da poesia, Alfredo Bosi (1977, p. 145) associa o lirismo de Rousseau à dramaticidade da sua retórica: "A resistência [...] ora [propõe] a melodia dos afetos em plena defensiva (lirismo de confissão, que data, pelo menos, da prosa ardente de Rousseau)", apontando-o como um dos precursores do gênero autobiográfico.

3 A questão certamente não é nova para a história da filosofia e, no interior dessa história, para a história da formação ou educação, uma vez que remete, desde os gregos, àquele elemento que traduz o eterno anseio de aprimorar e cultivar as possibilidades tipicamente humanas. Mas o que irá interessar aqui é como tal anseio adquire mutabilidade e especificidade de acordo com um determinado autor, criatura e criador do seu próprio tempo, como é o caso de Jean-Jacques Rousseau: uma estética da existência a qual orientaria o "eu" para que essa existência não apenas seja vivida, mas que o seja da melhor maneira possível conforme as leis da natureza propaladas por Rousseau. Isto representaria viver uma existência de forma ideal - pois é disso que se trata - e se conectaria de algum modo à beleza proporcionada pela harmonia e ordem que emanam do conceito de natureza manifesto nessa filosofia.

4 Entende-se por máscaras sociais o que Rousseau considera uma espécie de jugo da vida social (moral) advindo das relações entre as pessoas e da necessidade que tinham umas das outras devido à sua inevitável dependência entre si. Assim, Rousseau afirma que, em sociedade, os indivíduos assumem máscaras porque dependem uns dos outros para atingirem seus objetivos, já que não podem prover de tudo que precisam para viver (como é o caso do homem natural, o qual vivia na solidão e se bastava a si mesmo). Daí a constante menção do filósofo às relações baseadas na mentira, na inveja, na cobiça, na maldade, na comparação que os indivíduos realizavam entre si e os demais - originando a competição (motivada pela inveja), no egoísmo, entre outras inclinações artificiais emergentes da vida civil. 
6 Também conhecido como Segundo Discurso. O Primeiro Discurso é intitulado Discurso sobre as ciências e as artes. ROUSSEAU, Jean-Jacques. Discurso sobre as Ciências e as Artes [1750]. Tradução de Lourdes Santos Machado. São Paulo: Abril Cultural, 1973. (Coleção "Os Pensadores", XXIV).

$7 \quad$ No Discurso sobre a origem e os fundamentos da desigualdade entre os homens, Rousseau reflete sobre a solidão ao contrastar o hipotético estado de natureza do homem pré-social com o estado civil considerado por ele degenerado: "Depois de ter provado ser a desigualdade apenas perceptível no estado de natureza, e ser nele quase nula sua influência, resta-me ainda mostrar sua origem e seus progressos nos desenvolvimentos sucessivos do espírito humano. [...] Resta-me considerar e aproximar os vários acasos que puderam aperfeiçoar a razão humana, deteriorando a espécie, tornar mau um ser ao transformá-lo em ser social e, partindo de tão longe, trazer enfim o homem e o mundo ao ponto em que o conhecemos" (ROUSSEAU, 1973, p. 264). Em Emílio ou Da Educação, o problema do contraste entre natureza e cultura é retomado. Porém, no excerto a seguir, tal questão ganha maior dramaticidade e complexidade quando Rousseau, além de admitir que o destino humano é inexoravelmente social, confessa - contrariamente aos seus comentários habituais a respeito do tema - que um indivíduo solitário seria fatalmente infeliz vivendo em sociedade porque não estaria ligado a nenhum vínculo afetivo: "A fraqueza do homem torna-o sociável e nossas misérias comuns levam nossos corações à humanidade [...]. Todo apego é um sinal de insuficiência; se cada um de nós não tivesse nenhuma necessidade dos outros, não pensaria em se unir a eles. Assim, de nossa mesma imperfeição nasce nossa frágil felicidade. Um ser realmente feliz é um ser solitário; só Deus goza de uma felicidade absoluta; quem de nós, porém, tem alguma ideia do que seja isso? Se algum ser imperfeito pudesse bastar a si mesmo, de que gozaria ele? Estaria só, seria miserável. Não posso conceber que quem de nada precisa possa amar algo; não consigo conceber que quem nada ama possa ser feliz" (ROUSSEAU, 2004, p. 301). Em Emílio ou Da Educação, a problemática da solidão também desponta no elogio à educação solitária do jovem Emílio preconizada até o fim de sua infância.

8 Grifo do autor.

$9 \quad$ Grifo do autor.

10 ROUSSEAU, Jean-Jacques. Ensaio sobre a origem das línguas [1781]. Tradução de Lourdes Santos Machado. São Paulo: Abril Cultural, 1973. (Coleção "Os Pensadores", XXIV).

11 A respeito do desejo de transparência que extrai do próprio esgotamento a sua energia criadora, Lejeune observa sobre a retórica de Rousseau: "[...] é de fato meio repetitiva, mas é como a retórica do amor: nessas situações, sempre se imprime nova força a palavras que já foram usadas" (LEJEUNE, 2014, p. 84).

\section{Grifo do autor.}

13 RILKE, Rainer Maria. Cartas a um jovem poeta. In: Cartas a um jovem poeta e a canção de amor e de morte do porta-estandarte Cristóvão Rilke. Traduções de Paulo Rónai e Cecília Meireles. 4. ed. São Paulo: Globo, 2013.

14 ROUSSEAU, Jean-Jacques. Júlia ou a Nova Heloísa [1761]. Tradução e apresentação de Fúlvia Moretto. São Paulo, Campinas: Editoras HUCITEC e UNICAMP, 1994. 